\title{
The problem of admissibility of evidence in Indian civil proceedings
}

\author{
Anton Koshelev*, and Ekaterina Rusakova \\ RUDN University, Moscow, Russia
}

\begin{abstract}
The article deals with the problem of evidence and proof in civil proceedings in India. A number of foreign researchers focus on the issue of admissibility and inadmissibility of evidence in legal proceedings. In this regard, special attention is paid to the interpretation of different types of evidence and the legality of their inclusion or recusal in terms of judicial civil proceedings in India. Moreover, the situation is complicated by the global pandemic problem that makes the assessment of the validity of evidence more challenging for the judicial system of India and other countries in modern conditions.
\end{abstract}

\section{Introduction}

The problem of evidence admissibility has always been at the center of attention of foreign and domestic researchers due to the necessity to solve it and the highly debatable nature of assessing the evidence in the world's judicial systems. This difficulty is also faced by Indian law during civil disputes where every piece of evidence requires classification and detailed examination [6]. In this regard, the purpose of this article is to examine the problem of admissibility of evidence in Indian civil proceedings and to identify the key principles of admissibility of the submitted evidence in court proceedings.

The problem of admissibility of evidence in Indian civil proceedings is studied by such foreign researchers as S. Chen [2], T. Karia [4], T. Karia, A. Anand, B. Dhawan [3], J.K. Oberoi [5], S.K. Verma, Dr. Aditi Verma [7], A. Chaudhary [9] et al. Scholars have noted that the term "permissibility" has a general meaning of the state or quality of acceptability or acceptance. In civil litigation matters, this concept should be understood to mean anything that is admitted by a court to prove or disprove the facts alleged at trial. In other words, the admissibility of evidence implies that any document, testimony, or material evidence used in a trial is admissible. However, it is important to note that not all evidence can be admitted into the case file, but only that which is credible and relevant from the perspective of the court. According to Indian civil procedure, evidence is presented to the judge or jury to prove a point of view or an important event in the case, which can bring clarity to the trial so that it takes place in a lawful and unbiased manner.

Evidence can be seen as the "currency" with which one bears the burden of proof. To decide in a civil case to establish and prove issues of defence or mitigation, or the presumption of innocence, it is necessary to determine whether the evidence before it meets

\footnotetext{
* Corresponding author: KoshelevAA2012@mail.ru
} 
the required standards and parameters or whether it is sufficiently relevant in a given proceeding.

\section{Material and methods}

In Indian civil proceedings, as in many others, the judge considers all the evidence in a case to make a final decision, so often, even a single piece of evidence can affect the outcome of the proceedings. Such evidence must be sufficient and legally relevant to legal action at the request or request of the parties. In this regard, the term "evidence" means "to show clearly", "to certify", "to prove" [6].

Evidence in civil proceedings in India includes:

- all statements which the court permits or requires to be made before it by witnesses in connection with the facts of the case under investigation - oral evidence;

- all documents, including electronic records, submitted for examination by the court documentary evidence.

While deciding the court's admissibility in Indian civil proceedings, the following definition of admissibility is used as provided in Section 17 of the Indian Evidence Act, 1872 [6], which means the admission of evidence into the case file based on its proven validity and relevance.

Basant Singh v. Janki Singh case [1966] has formulated basic principles regarding admissibility of evidence in Indian civil proceedings which include the following:

- there is no distinction between a party's admission in a guilty plea and other subsequent admissions;

- confession made by a party to a lawsuit must be duly signed and acknowledged by that party, which may be used as evidence against that party in another lawsuit, but it cannot be conclusive;

- recognition cannot be presented in parts and can only be considered as a whole;

- confession can only be read in its entirety and no statement can be taken out of context to formulate an admission of a particular fact;

- confession connects the creator to the facts of the case;

- admissibility of a guilty plea can be established only if the guilty plea is recorded in the words of the accused or the person charged with the offence;

- for a confession to have a valid evidentiary effect, it must be voluntary;

- confession cannot be regarded as one made in ignorance of rights or under duress, in which

a person is influenced by lawful or unlawful coercion to liberty by the exercise of physical coercion; lawful civil liability, arrest or subrogation of a citizen; or unlawful commission of a crime, coercion to contract or the threatened use of threats;

- admission is limited in that it is prima facie evidence only (needing no further proof unless contrary evidence is introduced in court) and has no persuasive value;

- confessions that are clear, complete and relevant from the words of the accused or person charged with the crime are considered the best evidence of the facts presented.

There is some conflict between the concepts of "relevant" and "permissible" in the legal environment. Thus, the distinction between these terms is as follows: all admissible evidence is relevant, but not all relevant evidence is admissible. In this contextual sense, the term "relevance" is broader than the term "admissibility" because it refers to a generic concept, while admissibility refers to a generic concept.

In Indian civil proceedings, there are two main factors that are considered in determining the admissibility of evidence:

- relevance: the evidence must prove or disprove an important fact in the civil case. If the evidence does not relate to a particular fact, it is considered "irrelevant" and therefore irrelevant and therefore inadmissible in a particular proceeding; 
- reliability, which refers to the reliability of the source used as evidence. Generally, the reliability of the evidence is linked to the testimony of witnesses.

\section{Results}

What seems interesting is that in civil proceedings in India, it is permissible to involve persons mentioned by one of the parties in a particular suit. A third-party admission is considered relevant and admissible when a party involves another party in its validation to obtain information and accept the third party's testimony in the case. In the case of K.M. Singh v. Secretary Indian University Association [1992] has held that the opinion of a third party is taken into account when it is relied upon by one of the parties to the dispute. The opinion of a third party is taken into account because one party to the dispute endorses the opinion of a third party with the expectation that the other party will also participate in the interrogation.

An equally significant issue in the admissibility of evidence by a court in Indian civil proceedings is understanding the factors that determine its inadmissibility and non-inclusion in the case file. Such factors may include the following: unfair prejudice, waste of time, misrepresentation, hearsay evidence, evidence of the defendant's character, expert testimony, and privilege.

Within these factors, namely unfair bias, the word "biased" is used to mean a tendency to persuade based on experience rather than the evidence in a given case. Evidence that is "unfairly prejudicial" or prejudicial to the case without establishing any proper fact and offends the jury or judge without providing any material fact other than conjecture is often excluded from the trial.

During litigation, attorneys representing their clients tend to present evidence or witnesses that can lead to a waste of court time, thereby delaying time and preventing a final decision. Such witnesses or evidence shall be excluded from the proceedings. For example, a waste of time could include a lawyer engaging about twenty people to prove a person's honesty.

Evidence that would divert the jury's attention or the judge from the main issue or the merits of the case is considered misleading and is excluded from the trial. For example, debts to suppliers of materials and raw materials of a person engaged in entrepreneurial activities are irrelevant in considering a dispute about the production and sale of substandard products by that person.

Hearsay testimony relates to the fact that a person has not particularly personally seen or heard something about an event taking place but has received information about some event taking place from another person. Such evidence is not admissible in court because anyone can lie and accuse another person of saving someone or escaping punishment or greatly exaggerate/decrease certain facts, events, and actions against a background of emotional impression.

Evidence presented by the plaintiff to prove the character of the defendant having certain traits is excluded from the trial unless the defendant presents the character evidence first at trial.

Expert testimony is admissible only if it is originally given by an expert and not by a qualified professional. The latter cannot give expert testimony, as it is not admissible by the court and is not included in the case file.

The Court does not allow the privilege of attorneys or the receipt of any confidential information from them. Such information is confidential and could lead to perjury of counsel, and is therefore considered inadmissible in court.

In 2019, the world was facing a serious challenge that has put the entire global community in need of online interaction, and the judicial system is no exception [1]. Thus, given the spread of coronavirus infection, evidence in court through face-to-face testimony was largely 
limited. Consequently, video conferencing has become actively adopted and accepted in civil proceedings in India as an extremely effective tool for gathering evidence (face-to-face testimony) because it avoids unnecessary postponement of cases and saves the parties from the cost of transportation and other inconveniences that may arise. However, the most important advantage is that litigants may not be present during the trial to avoid infecting themselves or others if any of them has the infection, which has become necessary given the current world situation.

The validity of videoconferencing as evidence was highlighted in Amitabh Bagchi v Ena Bagchi [2005] where the court held that physical presence is not mandatory and the term "presence" should be interpreted more broadly so that video presence can also be considered as a means for participants in a trial to provide evidence.

In Liverpool and London Steamship Protection and Indemnity Association Ltd v MV 'Sea Success I' \& anor [2005], the Bombay High Court granted the plaintiff's application to give evidence by videoconference because the witness was in the UK with his two minor children and could not be physically present in India.

In Bodala Murali Krishna v Smt Badola Prathima [2007], the Andhra Pradesh Supreme Court similarly allowed the video presence of a US resident witness by videoconference. The Court pointed out that there was no valid objection to the use of videoconferencing in civil cases as long as the necessary means along with guaranteed accuracy were available.

Moreover, the Supreme Court in Dr Kumar Saha v Dr Sukumar Mukherjee [2011] (medical negligence case) went even further and ordered the recording of testimony and cross-examination of foreign expert witnesses by Internet conference instead of video conference, followed by a determination of the validity of said evidence in proceedings under the standardized process described in the Indian procedure involving the relevant Commission.

\section{Conclusion}

According to a study by J.K. Oberoi [5], the modern tools currently available significantly reduce the frequent obstacles and legal uncertainties associated with the use of information technology, including the cost of purchasing equipment, other technological issues related to data protection, the confidentiality of documents and evidence presented in proceedings, and the privacy of parties. Based on the acceptance and positive response from the Indian legal community, the use of videoconferencing in Indian civil dispute resolution will continue to grow, acting as a response to the contemporary challenges and needs of the people of the country [8].

Thus, it may be concluded that the judicial system in India has clearly defined the place of evidence in civil proceedings as well as their types and factors of admission or nonadmission in the particular litigation. However, with the emergence of new challenges, civil litigation is actively adapting to the obstacles that stand in its way of justice and impartiality, which is why it now seems quite natural and legitimate to introduce not only electronic evidence but also video conferencing as evidence in a particular proceeding, as evidenced not only in India but also in the world practice.

This work was financially supported by the Grant of the President of the Russian Federation No. NSh2668-2020.6 "National-Cultural and Digital Trends in the Socio-Economic, Political and Legal Development of the Russian Federation in the 21 st Century." 


\section{References}

1. E.P. Rusakova, E.E. Frolova, S.S. Zankovsky, E.V. Kupchina, 6th International Conference on Education, Social Sciences and Humanities, 754 (2019)

2. S. Chen, International Commentary on Evidence, 10(1), 1 (2014)

3. T. Karia, A. Anand, B. Dhawan, Digital Evidence and Electronic Signature Law Review, 12, 33 (2015)

4. T. Karia, Digital Evidence and Electronic Signature Law Review, 5, 214 (2008)

5. J.K. Oberoi, Legal briefing. The Legal 500

6. The Indian Evidence Act, 1872

7. S. K. Verma, Verma Aditi Dr, Indian Journals, 9(4), 86 (2010)

8. E. P. Rusakova, A.O. Inshakova, International Journal for Quality Research, 15(1), 273 (2021)

9. A. Chaudhary, Admissibility of Scientific Evidence under Indian Evidence Act 1872 